\title{
RANCANG BANGUN DAN REKAYASA PENGOLAHAN LIMBAH CAIR RUMAH SAKIT (Studi Kasus Rumah Sakit Kristen Tayu, Pati)
}

\author{
${ }^{1}$ Stephanus Agus Nurdijanto, ${ }^{1,2}$ Purwanto, ${ }^{1,2}$ Setia Budi Sasongko. \\ ${ }^{1}$ Program Magister Ilmu Lingkungan Universitas Diponegoro \\ ${ }^{2}$ Jurusan Teknik Kimia Fakultas TeknikUniversitas Diponegoro
}

\begin{abstract}
ABSTRAK
Limbah cair Rumah sakit Kristen Tayu Pati terdiri atas limbah cair infeksius dan non infeksius yang memberikan Nilai COD (Chemical Oxygen Demand) cukup tinggi sebesar 121,60 mg/l yang menunjukkan kandungan senyawa organik yang cukup tinggi.Limbah Cair tersebut terbuang ke sungai di Desa Sambiroto Kecamatan Tayu,Pati tanpa diolah dengan Instalasi Pengolahan Air Limbah (IPAL) .Proses Aerob dan Anaerob yang menjadi dasar teori memberikan solusi bahwa Proses Pengolahan Limbah Cair Rumah Sakit menggunakan sistim Trickling Filter dan Baffled Tank Reaktor . Penelitian ini dilakukan dengan Sistem Batch dan Sistim Kontinyu, dengan Analisa SWOT, Kekuatan dan Kelemahan cenderung memberikan Nilai Skor total pada Kelemahan : 1,0 sedangkan Peluang dan Ancaman memberikan deregulasi skor total pada Peluang 0,8 untuk membuat IPAL. Dari hasil peneitian didapatkan bahwa dengan menggunakan lumpur aktif melalui sistim Batch dan Kontinyu didapatkan hasil sesuai dengan baku mutu yang diharapkan perlu dilakukan pengelolaan dan pemantaun hubungan serta evaluasi dan analisis terhadap pola limbah cair di rumah sakit ,desain rancang bangun IPAL, dan sisa limbah IPAL sebaiknya diproses.
\end{abstract}

Kata Kunci : waste, hospital treatment, waste management

\section{PENDAHULUAN}

Pelaksanaan pembangunan yang mempunyai wawasan lingkungan hidup tidak terlepas dari adanya tindak lanjut sarana dan prasarana pengelolaan lingkungan. Pelayanan di bidang kesehatan merupakan bagian dalam upaya peningkatan derajat kesehatan masyarakat. Dampak negatif pada umumnya terjadi karena limbah padat dan cair yang dapat mengganggu kegiatan operasional dan menurunkan tingkat kesehatan masyarakat. Limbah Padat terbagi atas Limbah Padat Non infeksius, Limbah Padat infeksius, Bahan Berbahaya dan Beracun (B3), serta Limbah Cair yang terdiri atas Limbah Cair Infeksius dan Limbah Cair Non Infeksius. Limbah ini memberikan Nilai Parameter yang berdampak, antara lain BOD (Biological
Oxygen Demand) dan COD (Chemical Oxygen Demand).

Kegiatan operasional Rumah Sakit Kristen Tayu di Desa Sambiroto Kecamatan Tayu Kabupaten Pati belum mempunyai Instalasi Pengolahan Air Limbah (IPAL). Hal ini memiliki potensi dampak negatif yang dapat mengganggu lingkungan sekitar.

Air Limbah Rumah Sakit Kristen Tayu saat sekarang ini terbuang lepas ke sungai sebanyak $52.8 \mathrm{~m} 3 /$ hari yang berasal dari kegiatan medik yaitu dari Ruang Perawatan, Ruang Laboratorium, Ruang Poliklinik, Ruang IGD, Ruang Bedah, Ruang Bersalin, Ruang Radiologi, serta dari kegiatan Non Medik yang berasal dari Toilet Umum(70 \%) masuk ke septic tank sedangkan sisanya $30 \%$ masuk ke IPAL untuk diproses. Limbah yang datang dari Ruang Laundry, Ruang Kantor, Ruang Dapur, ruang lain lain tanpa pengolahan sesuai dengan teknologi yang ada, Sungai lokasi pembuangan 
melewati tengah-tengah lokasi kegiatan rumah sakit. Dari data yang diperoleh didapatkan bahwa karakteristik limbah rumah sakit untuk $\mathrm{pH}: 7,32$, TDS 1250 $\mathrm{mg} / \mathrm{l}$, Ammoniak 18,37 mg/l, BOD 40,50 mg/l, dan COD 121,60 mg/1 .

Permasalahan dalam Penelitian adalah manajemen limbah cair belum sempurna/belum layak dan belum ada data teknis yang valid untuk perancangan IPAL.

Bentuk Limbah Cair adalah Limbah Klinis yang sering menimbulkan masalah di rumah sakit. Bentuknya adalah Benda Tajam, Limbah infeksius, Jaringan Tubuh, Limbah Cititoksik, Limbah Farmasi, Limbah Kimia, Limbah Radioaktif, Limbah Plastik dan Limbah Padat atau non infeksius lainnya, sedangkan untuk Limbah Cair adalah merupakan hasil pelaksanaan kegiatan Limbah klinis baik yang mirip hasil pencucian dan sebagainya.

Dampak yang terjadi akibat kegiatan Rumah Sakit adalah adanya kontaminasi di Air, Udara, Ruangan dan Bangunan. Peralatan dan Perlengkapan lainnya, Manusia / Individu/ Personalia dan Pasien/ Individu Sakit. Tujuan penelitian adalah untuk merencanakan manajemen pengelolaan limbah rumah sakit dan IPAL berdasarkan data hasil penelitian laboratorium. Manfaat penelitan ini diharapkan dapat memberikan usulan pengolahan limbah cair rumah sakit serta mengurangi dampak negatif yang mungkin timbul sehingga dapat dicapai suatu rumah sakit yang berwawasan lingkungan yang diakumulasikan dalam Pelaksanaan Rancang Bangun dan Rekayasa Model.

Proses ini dapat dibedakan dalam dua jenis yaitu: a) Proses aerob, yaitu proses yang berlangsung dengan hadirnya oksigen. Bahan-bahan organik yang terdapat dalam limbah dapat dipecah oleh mikroorganisme aerob menjadi bahan yang tidak mencemari. Pemecahan ini berlangsung dalam suasana aerob (ada oksigen).

Bahan-bahan organik + mikroorganisme aerobik $+\mathrm{O}_{2}$.

Oksidasi

$$
\begin{aligned}
& \mathrm{C}_{\mathrm{x}} \mathrm{H}_{\mathrm{y}} \mathrm{O}_{\mathrm{z}}+\mathrm{O}_{2} \rightarrow \mathrm{CO}_{2}+\mathrm{H}_{2} \mathrm{O} \\
& \mathrm{C}_{\mathrm{x}} \mathrm{H}_{\mathrm{y}} \mathrm{O}_{\mathrm{z}}+\mathrm{NH}_{3}+\mathrm{O}_{2} \rightarrow \text { sel-sel } \\
& \text { mikroorganisme }+\mathrm{CO}_{2}+\mathrm{H}_{2} \mathrm{O} \\
& \text { Sel mikroorganisme }+\mathrm{O}_{2} \rightarrow \mathrm{CO}_{2}+\mathrm{H}_{2} \mathrm{O}+\mathrm{NH}_{3}
\end{aligned}
$$

b) Proses anaerob, yang berlangsung tanpa adanya oksigen. Proses fermentasi anaerob pada dasarnya adalah proses yang mengubah senyawa organik menjadi metana $\left(\mathrm{CH}_{4}\right)$ dan karbon dioksida $\left(\mathrm{CO}_{2}\right)$ tanpa kehadiran oksigen $\left(\mathrm{O}_{2}\right)$. Reaksi yang utama adalah konversi glukosa menjadi asam asetat seperti pada persamaan reaksi berikut ini :

$\mathrm{C}_{6} \mathrm{H}_{12} \mathrm{O}_{6}+2 \mathrm{H}_{2} \mathrm{O} \rightarrow 2 \mathrm{CH}_{3} \mathrm{COOH}+2 \mathrm{CO}_{2}+4 \mathrm{H}_{2}$

$\mathrm{CH}_{3} \mathrm{CH}_{2} \mathrm{COOH}+2 \mathrm{H}_{2} \mathrm{O} \rightarrow 2 \mathrm{CH}_{3} \mathrm{COOH}+2 \mathrm{CO}_{2}+3 \mathrm{H}_{2}$ (2)

$2 \mathrm{CH}_{3} \mathrm{CH}_{2} \mathrm{OH}+\mathrm{CO}_{2} \rightarrow 2 \mathrm{CH}_{3} \mathrm{COOH}+\mathrm{CH}_{4}$

$\mathrm{CH}_{3} \mathrm{CH}_{2} \mathrm{OH}+\mathrm{H}_{2} \mathrm{O} \rightarrow \mathrm{CH}_{3} \mathrm{COOH}+2 \mathrm{H}_{2}$

$\mathrm{CH}_{3} \mathrm{COOH} \rightarrow \mathrm{CH}_{4}+2 \mathrm{H}_{2} \mathrm{O}$

\section{Anaerob Baffled Tank Reaktor}

Reaktor jenis ini dikembangkan oleh Bachman dan Mc Carty di Stanford University tahun 1982, berbentuk tangki persegi panjang, dibagi 4 kompartemen berukuran sama. Masing-masing kompartemen dipisahkan dinding, atap dan dasar tangki. Zat cair dialirkan menuju ke atas lalu ke bawah antar dinding dan menuju ke atas lagi melalui sludge anaerobik blanket hingga melewati kompartemen ke 4 . Terjadilah kontak antar air limbah dengan biomassa aktif.

Efisiensi Proses Pengolahan: Menurut Droste (1997) efisiensi pengolahan limbah merupakan rasio antara kandungan organik yang disisihkan melalui proses pengolahan dengan konsentrasi awal. Efisiensi konsentrasi pengolahan limbah dihitung sebagai berikut : $\eta=\frac{S o-S e}{S o}$

dimana $\eta$ adalah efisiensi (\%)

So adalah konsentrasi COD influen

Se adalah konsentrasi COD efluen

METODA PENELITIAN

Pengambilan Data Primer dilakukan dengan cara konfirmasi pada pihak pengelola rumah sakit, pengamatan beban, percobaan 
laboratorium untuk mengetahui model pengolahan limbah. Data diperoleh dari hasil laboratorium berdasarkan penelitian, pengamatan, dan perhitungan kemudian hasil penelitian dianailsis dengan pendekatan deskriptif, selanjutnya dibuat analisis SWOT (Strenght, Weakness, Opportunity, dan Strength) terhadap sistem dan prosedur pengelolaan dengan memakai scoring dan bobot kepentingan/prioritas, urgensi faktor internal, maupun eksternal.

Penelitian ini dalam skala laboratotium dengan sistim batch dan kontinyu dalam variasi waktu tinggal $(1,2,3,4,6,8,15,30$ hari), perbandingan lumpur aktif dengan air limbah (MLSV) 0,25 1 lumpur/ liter suspensi, (MLSV) 0,50 1 lumpur/ liter suspensi dan (MLSV) 0,25 1 lumpur/ liter suspensi,) pada reaktor anaerob. Rancangan percobaan penelitian dilakukan dengan Sistim Batch karena dilaksanakan dalam jumlah skala kecil dan bertempat di laboratorium. Untuk merencanakan Pembuatan IPAL skala besar dilakukan dengan Sistim Kontinyu. (lihat Tabel 1)

Tabel 1. Rancangan dan Hasil Percobaan Sistem BATCH dan KONTINYU

\section{KONTINYU}

Gambar: 1. Anaerob baffled reactor

Keterangan:Volume 100 liter, panjang : $120 \mathrm{~cm}$, Lebar : $30 \mathrm{~cm}$, ketinggian Bak 70 $\mathrm{cm}$, Air ;50 cm, Waktu : 1,2,3,4,6,8, 15 dan 30 hari

Volume Lumpur ( 1 ) (MLSV) 0,25 1 lumpur/ liter suspensi, (MLSV) $0,50 \quad 1$ lumpur/ liter suspensi, (MLSV) $0,75 \quad 1$ lumpur/ liter suspensi

\section{ВАТСH}

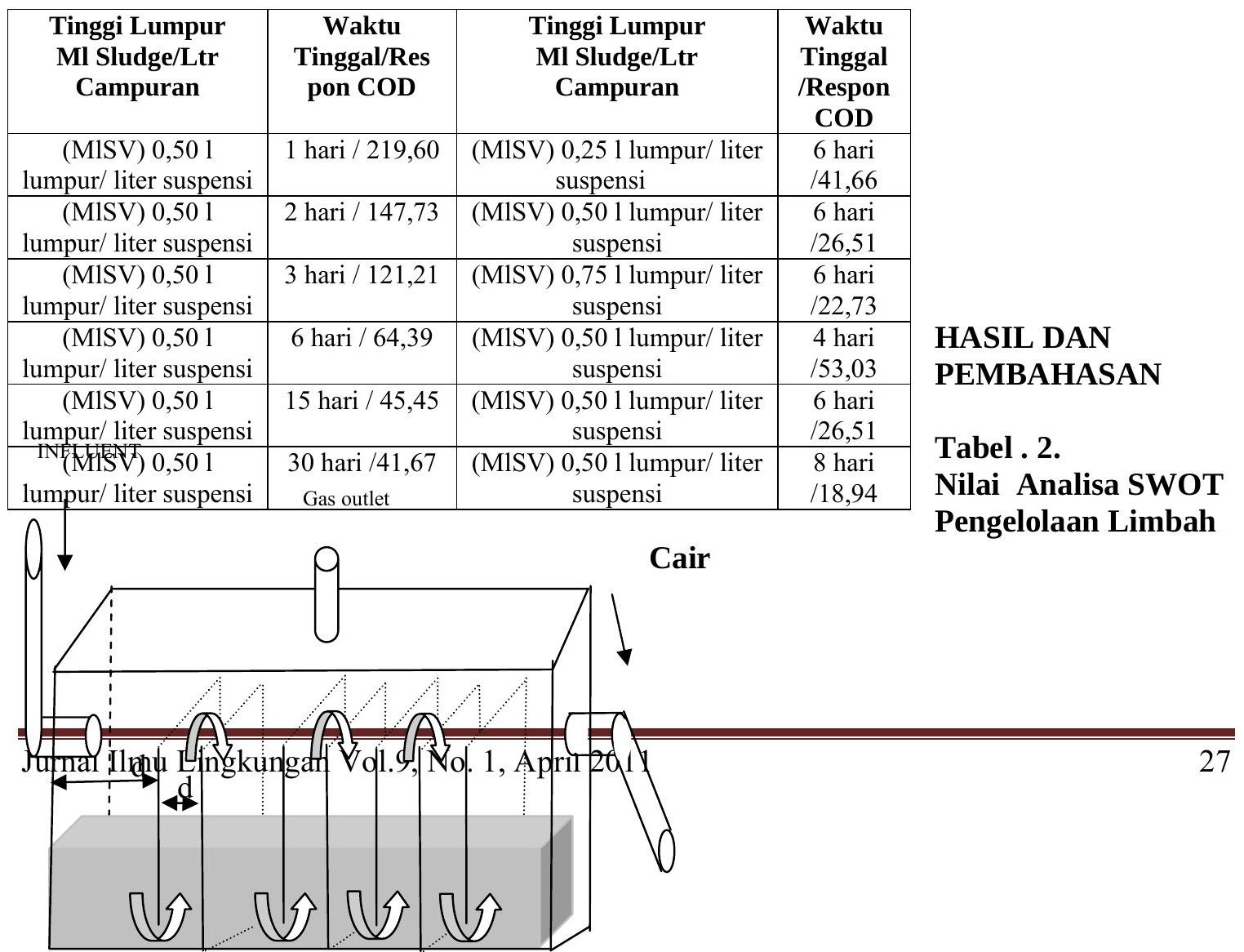




\begin{tabular}{|l|l|c|c|c|}
\hline No & \multicolumn{1}{|c|}{ Keterangan } & Bobot & Rating & Skor \\
\hline 1 & Total Kekuatan & 100 & & 2.8 \\
\hline 2 & Total kelemahan & 100 & 0 & 3,8 \\
\hline 3 & Nilai total & & & $(1.0)$ \\
\hline 4 & Total Anceluang & 100 & 0 & 3.0 \\
\hline & Nilai Skor Total & 100 & 0 & 2.2 \\
& (Peluang - Ancaman ) & & & $(0,8)$ \\
\hline
\end{tabular}

Tabel 4.

Effisiensi Penurunan COD Pada Reaktor Anaerob,Sistim Kontinyu

\begin{tabular}{|l|l|l|}
\hline No & $\begin{array}{l}\text { Waktu } \\
\text { Tinggal }\end{array}$ & $\begin{array}{l}\text { Efisiensi COD (\%) (Lumpur) } \\
\text { (MISV) 0,50 I lumpur/ liter suspensi }\end{array}$ \\
\hline 1 & 4 & 76,71 \\
\hline 2 & 6 & 50,01 \\
\hline 3 & 8 & 72,22 \\
\hline
\end{tabular}

Tabel 3.

\section{Pengaruh Effisiensi Penurunan COD}

Reaktor, Anaerob, Sistim Batch

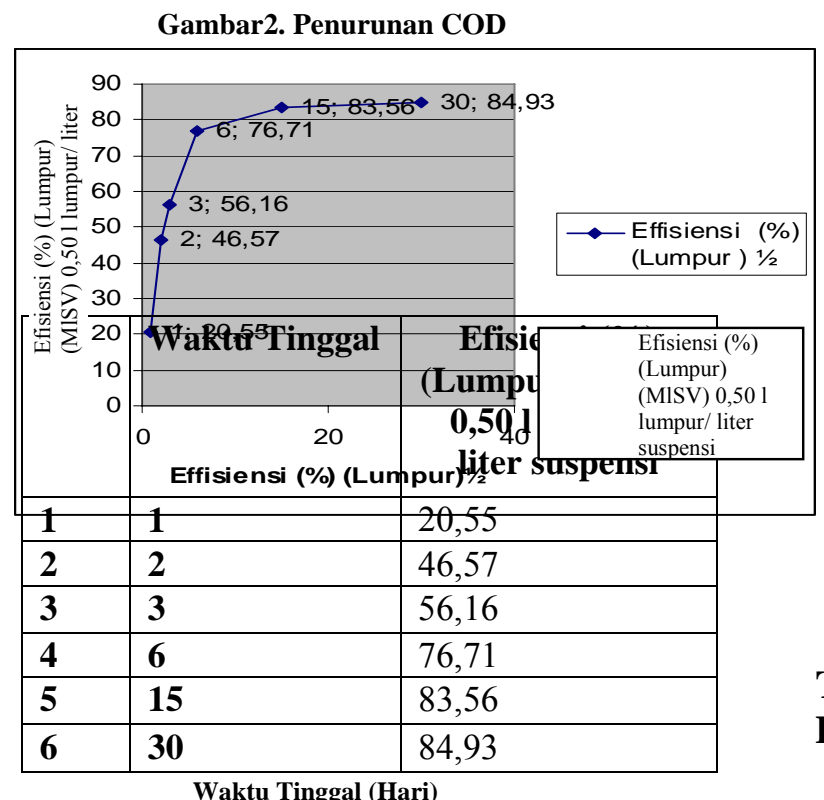

Gambar 3. Sistem Kontinyu

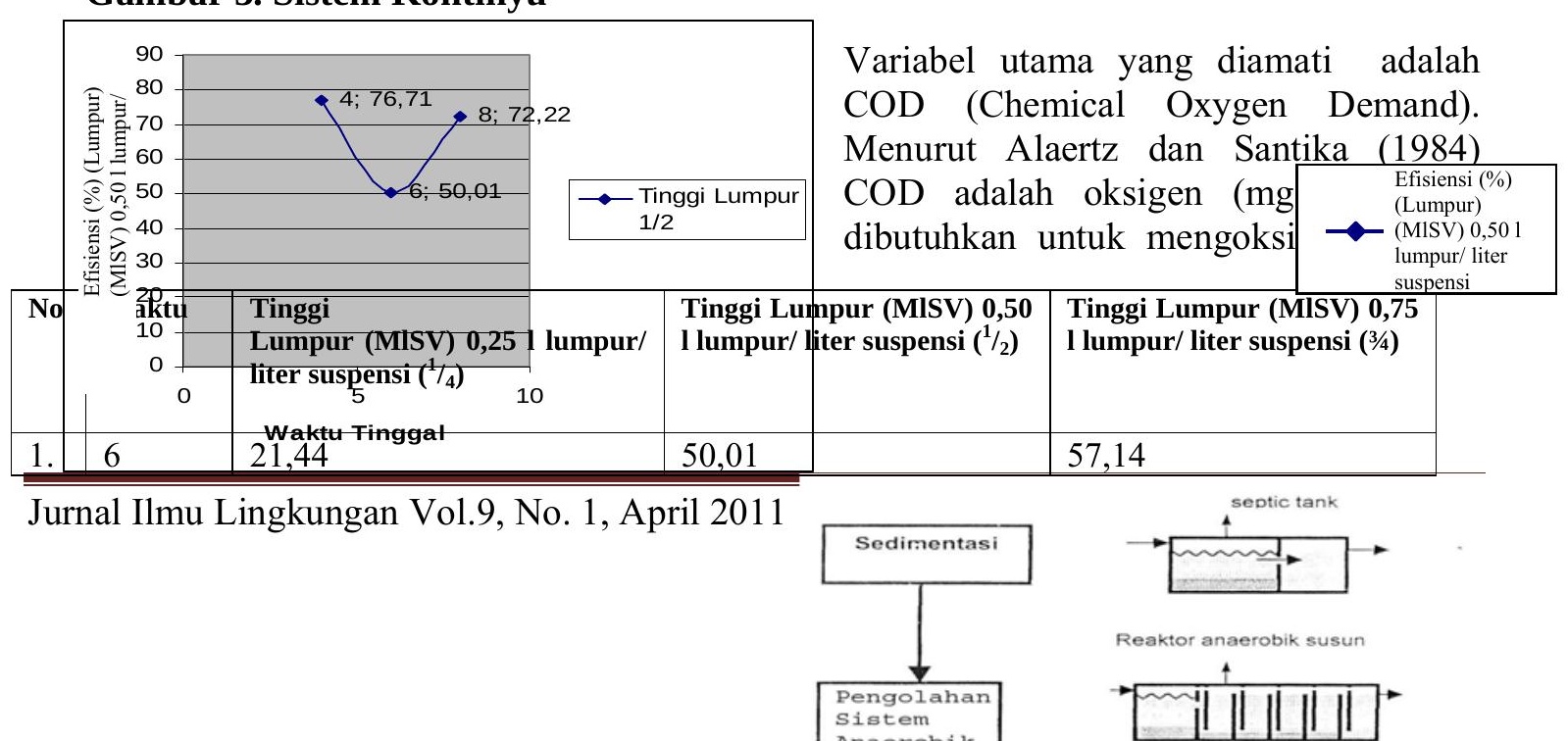

Tabel 5. Effisiensi Penurunan COD (\%) Pada Reaktor Anaerob

\section{Analisis COD}

Variabel utama yang diamati adalah COD (Chemical Oxygen Demand). Menurut Alaertz dan Santika (1984) COD adalah oksigen (mg Efisiensi $(\%)$ dibutuhkan untuk mengoksi $\longrightarrow$ (MISV) 0.501 (Lumpur) (M1SV) 0,50 1 lumpur/ liter suspensi 
organik yang ada dalam 1 liter sampel air. Konsentrasi COD dihitung dengan persamaan : $\mathrm{COD} \quad\left(\mathrm{mg} \quad \mathrm{O}_{2} / \mathrm{I}\right)=$ $\frac{(a-b) \times(N \times 8000)}{(m l) \text { sampel }}$

Dimana :

$\mathrm{a}=$ volume FAS untuk titrasi blanko

$\mathrm{b}=$ volume FAS yang digunakan untuk titrasi sampel

$\mathrm{N}=$ normalisasi larutan FAS

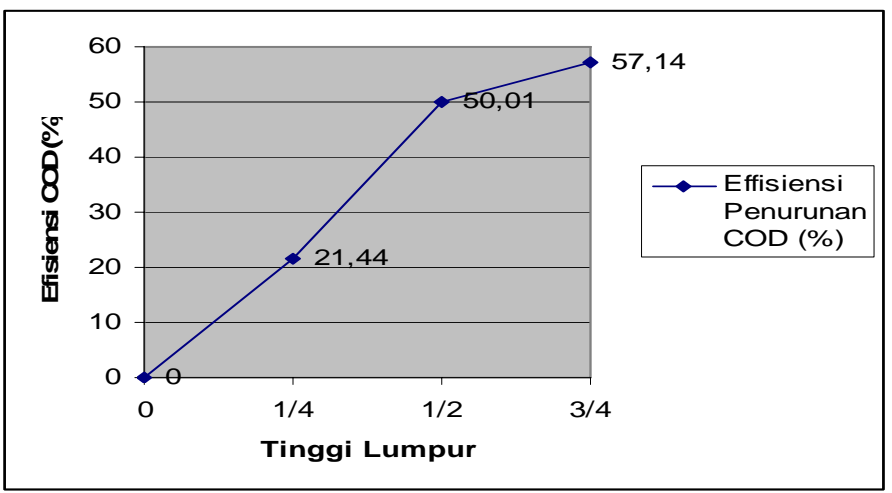

Gambar 4.

Efisiensi Penurunan COD

Pada Reaktor Anaerob
Gambar 6.

Desain Rancang Bangun Sistem Pengolahan Air Limbah Rumah Sakit 


\section{KESIMPULAN}

Dari Analisa SWOT didapatkan hasil bahwa manajemen pengelolan limbah cair harus dilaksanakan di Rumah Sakit Kristen Tayu Pati karena belum mempunyai Instalasi Pengolahan Air Limbah (IPAL). Untuk Skala Laboratorium lebih baik memakai Sistim Batch sedangkan sistim kontinyu lebih baik untuk skala pengolahan limbah cair skala besar.

\section{SARAN}

Dilakukan pengelolaan dan pemantauan hubungan, serta evaluasi dan analisis terhadap pola limbah cair di Rumah Sakit tersebut. Usaha untuk pembuatan IPAL dengan cara : Sistem Septic tank, Baffle Reactor, Filter anaerobik, Reactor Anaerobik susun , dekomposis aliran aerobik, dan kolam aerobik .

\section{REKOMENDASI}

Pengolahan Air Limbah dengan sistim batch dan kontinyu pada reaktor anaerob dapat memberikan konstribusi terhadap penurunan baku mutu . Sisa lumpur aktif yang sudah tidak terpakai dalam proses pengolahan air limbah dibakar dengan incenerator.

\section{DAFTAR PUSTAKA}

Alaerts, G dan Santika, SS. 1984. Metode Penelitian Air. Usaha Nasional . Surabaya

Anonim, Dirjen PPM dan PLP, 1990. Pedoman Sanitasi Rumah Sakit Di Indonesia. Departemen Kesehatan Republik Indonesia, Jakarta.

Astuti , AD dan Asis H Djajadiningrat. 2000. Model Matematika Penyisihan Subtrat Dalam Bioreaktor Hibrid Anaerobik Yang Mengolah Air Buangan mengandung Bahan Organik tinggi. Jurnal Purifikasi Vol 1 No.3.Mei 2000. Surabaya .
Chariton, AP dan Wahyono HADI. 2000.

Studi Pertumbuhan Bed Lumpur Kaitannya dengan Produksi Biogas pada Pengolahan Limbah Pabrik Tahu dengan Reaktor Horizontal. Jurnal Purifikasi Vol.1 No.5 September 2000. Surabaya.

Goe F Book and Janet S Butel , 2001. Surface Water Hospital Quality, The Macmillian Press Ltd London .

Hariadi Agustinus, 1996. Sistem pengolahan Limbah Bahan Berbahaya dan beracun rumah Sakit. Direktorat jenderal pengelolaan Limbah B3 Badan pengendalian dampak Lingkungan. Jakarta.

Hari Kusnanto, 1997. Pengendalian Infeksi Nosokomial, Magister Manajemen Rumah Sakit Pasca Sarjana UGM, Yogyakarta.

Kemas, Ali Hanafiah, Rancangan Percobaan Aplikatif , 2005, Divisi Buku Perguruan Tinggi, PT RajaGrafindo Persada, Jakarta . 